\title{
MEMBANGUN APLIKASI REKAM MEDIS PASIEN PADA KLINIK PRATAMA MELANIA
}

\author{
Marlon Brando Silalahi \\ Teknik Informatika,Fakultas Teknik dan Ilmu Komputer, Universitas Indraprasta PGRI Jakarta \\ Jalan Raya Tengah No 80, Kelurahan Gedong, Pasar Rebo, Jakarta Timur \\ marlonbrandosilalahi@gmail.com
}

\begin{abstract}
ABSTRAK
Permasalahan yang ada di Klinik Pratama adalah penyimpanan data pasien dan rekam medis yang masih dalam bentuk arsip sehingga memperlambat petugas dalam proses pencarian data tersebut. Selain itu, Pelaporan yang diberikan kepada pimpinan klinik sering sekali mengalami keterlambatan dikarenakan data yang tersimpan masih dicatat didalam buku. Tujuan merancang suatu aplikasi rekam medis pasien dengan tujuan untuk memproses pengolahan data rekam medis pasien yang ada saat ini. Perangkat aplikasi yang telah dibuat dengan bahasa pemrograman Java NetBeans 8.0.2 dan penyimpanan data pada database MySQL dapat memberikan kelancaran dalam proses menginput dan penyimpanan data-data serta laporan-laporan yang diberikan kepada pemilik klinik. Dengan menggunakan metode pengembangan sistem yaitu Waterfall dalam penelitian ini adalah dengan tahapantahapan seperti rekayasa sistem, analisis, desain, coding, testing, dan maintenance. Hasil dari penelitian ini menciptakan suatu aplikasi yang baru pada Klinik Pratama Melania yang menangani proses pencatatan dan pelaporan pasien sehingga dapat membantu admin klinik dan aplikasi ini dapat memudahkan admin klinik dalam proses pembuatan laporan yang diberikan kepada pimpinan klinik setiap bulannya.
\end{abstract}

Kata Kunci: Aplikasi, Rekam Medis, Pasien, Desktop

\section{ABSTRACT}

The problem at the Pratama Clinic is the storage of patient data and medical records which are still in archive form so that it slows down the officers in the process of searching for the data. In addition, reports given to clinical leaders often experience delays because the stored data is still recorded in the book. The purpose of designing a patient medical record application with the aim of processing the current patient medical record data processing. Application tools that have been created using the Java NetBeans 8.0.2 programming language and data storage in the MYSQL database can provide a smooth process for inputting and storing data and reports provided to clinic owners. By using the system development method, namely Waterfall, in this research, the stages are systems engineering, analysis, design, coding, testing, and maintenance. The results of this study create a new application at the Melania Primary Clinic which handles the process of recording and reporting patients so that it can help the clinic admin and this application can facilitate the clinic admin in the process of making reports that are given to the clinic leadership every month.

Key Word: Application, Medical Record, Patient, Desktop

\section{PENDAHULUAN}

Perkembangan teknologi komputer pada saat ini sudah banyak dibutuhkan penggunaannya karena dapat mempermudah dalam pengaksesan jaringan-jaringan yang dapat dilakukan untuk perpindahan dari sebuah data menjadi informasi (Rahmat Tullah, 2019). Kemampuan pada teknologi dapat mempermudah kita untuk lebih cepat mendapatkan data dan informasi. Komputer tidak hanya digunakan dalam bidang perbankan, transportasi, pendidikan, industri, tetapi juga dalam bidang kesehatan. Dalam bidang kesehatan, komputer sangat dibutuhkan untuk menginput dan menyimpan data pasien serta data rekam medis (Handayani \& Feoh, 2016).

Klinik Pratama Melania merupakan salah satu pelayanan publik yang membutuhkan komputer pada saat ini. Tidak hanya menginput dan menyimpan data pasien, komputer juga dapat mempermudah dalam pengolahan data pasien, penyimpanan hasil rekam medis pasien dan dalam membuat laporan (Sofica, Agista, Ningsih, \& Septiani, 2019). Dengan adanya komputer diharapkan dapat membantu dalam pelayanan 
yang akan diberikan kepada pasien dengan begitu pelayanan yang diberikan dapat semaksimal mungkin. Tujuan utama dari adanya Klinik Pratama Melania adalah menyediakan layanan kesehatan yang bermutu namun dengan biaya yanng relatif terjangkau untuk masyarakat, terutama masyarakat dengan kelas ekonomi menengah ke bawah (Syofian \& Widyantoro, 2018).

Klinik Pratama Melania merupakan sebuah klinik yang berlokasi di Jl. Ki Hajar Dewantara No.110A, Ciputat, Kec. Ciputat, Kota Tangerang Selatan, Banten 15411. Saat ini, dokter-dokter yang melakukan praktek di Klinik Pratama Melania diantaranya adalah dr. Resya. Adapun beberapa layanan kesehatan yang dapat Anda temukan di Klinik Pratama Melania adalah Gigi, Laboratorium, Kedokteran Gigi Anak, Konservasi Gigi, Penyakit Dalam, dan Umum.

Pelayanan pasien pada Klinik Pratama Melania yang masih dilakukan secara manual sehingga kurang memadai perkembangan klinik didalam menunjang dunia kesehatan. Sering terjadinya pengulangan dalam penyimpanan data dan pembuatan laporan yang masih membutuhkan waktu yang cukup lama sehingga hal ini di nilai kurang efisien (Fatkhudin \& Alifiani, 2017).

Dengan permasalahan tersebut, perlu ada nya suatu sistem yang terkomputerisasi dalam penyelesaiannya. Sistem adalah sekelompok unsur yang erat hubungannya satu dengan yang lain, yang berfungsi bersama-sama untuk mencapai tujuan (Sutabri, 2012). Sistem merupakan suatu kumpulan dari komponenkomponen yang membentuk satu kesatuan (Tyoso, 2016). Pembangunan sistem adalah sekumpulan aktivitas yang menggambarkan secara rinci bagaimana sistem akan berjalan. Hal itu bertujuan untuk menghasilkan produk perangkat lunak yang sesuai dengan kebutuhan user (Satzinger, J. W., Jackson, R. B., Burd, n.d.).

Dengan adanya komputer diharapkan dapat membantu dalam pelayanan yang akan diberikan kepada pasien dengan begitu pelayanan yang diberikan dapat semaksimal mungkin (Fatkhudin \& Alifiani, 2017). Tujuan utama dari adanya Klinik Cireundeu Medika adalah menyediakan layanan kesehatan yang bermutu namun dengan biaya yang relatif terjangkau untuk masyarakat, terutama masyarakat dengan kelas ekonomi menengah ke bawah (Rahmat Tullah, 2019).

Diharapkan dengan adanya suatu sistem informasi dapat menangani permasalahan yang ada di perusahaan tersebut. Sistem adalah setiap sesuatu terdiri dari obyek-obyek, atau unsur-unsur, atau komponen-komponen yang bertata kaitan dan bertata hubungan satu sama lain, sedemikian rupa sehingga unsur-unsur tersebut merupakan satu kesatuan pemrosesan atau pengolahan yang tertentu. (Prasojo, 2011)

Perancangan sistem aplikasi yang baru pada Klinik Pratama Melania yang menangani proses pencatatan dan pelaporan pasien sehingga dapat membantu admin klinik. Sistem informasi dengan menggunakan bahasa pemrograman Java dan database MySQL agar semua data dapat tersimpan dengan baik dan rapih sehingga memudahkan admin klinik dalam proses pencarian data.

\section{METODE PENELITIAN}

Peneliti menggunakan metode Grounded Research dalam penyelesaian penelitian ini. (Sugiyono, 2016) Metode grounded research yaitu suatu metode penelitian yang berdasarkan fakta dengan tujuan dapat menetapkan konsep, mengembangkan teori, pengumpulan dan analisis data dalam waktu yang bersamaan. Sedangkan metode observasi (pengamatan) merupakan metode pengumpulan data yang dilakukan secara sistematis dan sengaja melalui pengamatan dan pencatatan serta gejala objek yang diteliti langsung dilapangan, sebab metode observasi merupakan salah satu teknik penelitian yang sangat penting bagi seorang peneliti secara langsung dilapangan. Pengamatan ini dilakukan secara langsung merupakan alat ampuh untuk menguji suatu kebenaran.

Dalam mengumpulkan data dan informasi yang diperlukan, penulis berusaha melakukan beberapa penelitian secara langsung ke Klinik Pratama Melania. Penulis bukan hanya mencari dan mengumpulkan data, tetapi juga langsung melakukan klasifikasi terhadap data tersebut, 
mengolah dan menganalisa data, membangun hipotesis menjadi teori.

\section{HASIL DAN PEMBAHASAN}

Alternatif Penyelesaian Masalah

Hasil dari pengembangan sistem informasi rekam medis Klinik Pratama Melania ini adalah sistem yang dapat bekerja secara terkomputerisasi baik dalam pembuatan kartu berobat pasien, pendataan pasien ketika mendaftar, kunjungan pasien setiap waktunya, menyimpan hasil diagnosa dokter, menyimpan data obat yang keluar dan masuk secara rinci, dan dalam menyimpan laporan setiap minggunya, serta dalam pelayanan pun dapat menjadi lebih baik dan semaksimal mungkin. Dan membuat penyimpanan data atau database agar data dapat lebih akurat serta dapat mengurangi kemungkinan kehilangan data.

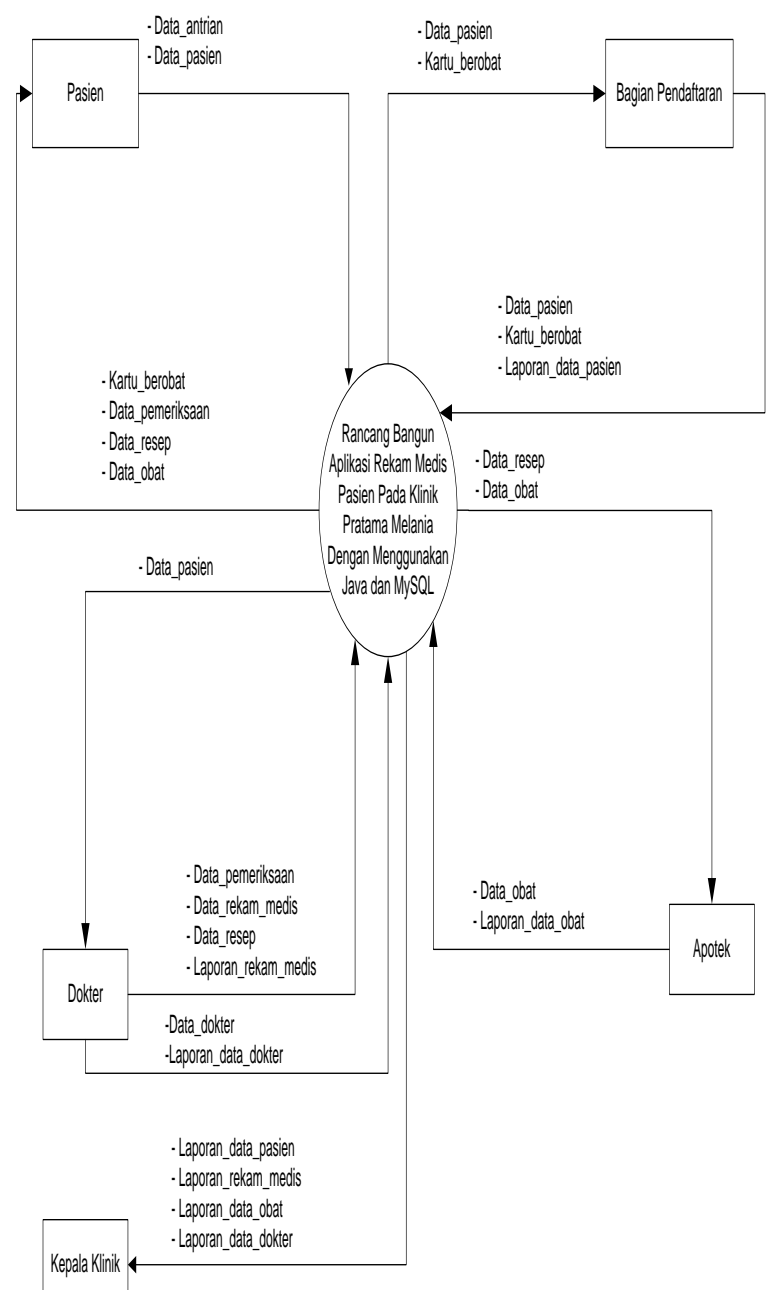

Gambar 1. Diagram Konteks

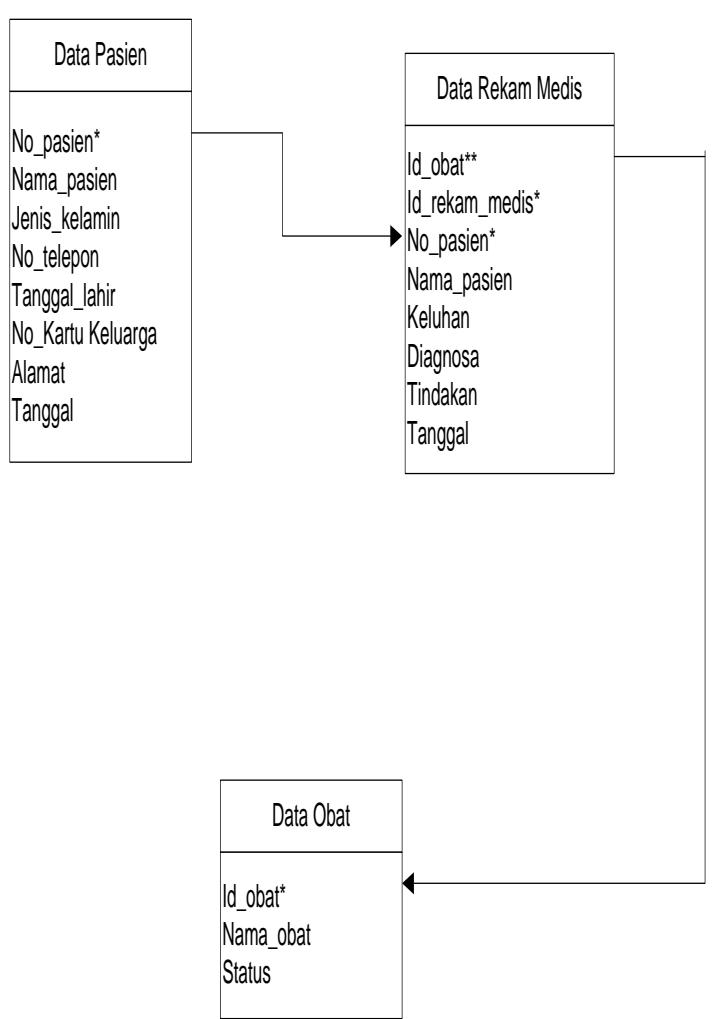

Gambar 2. Normalisasi

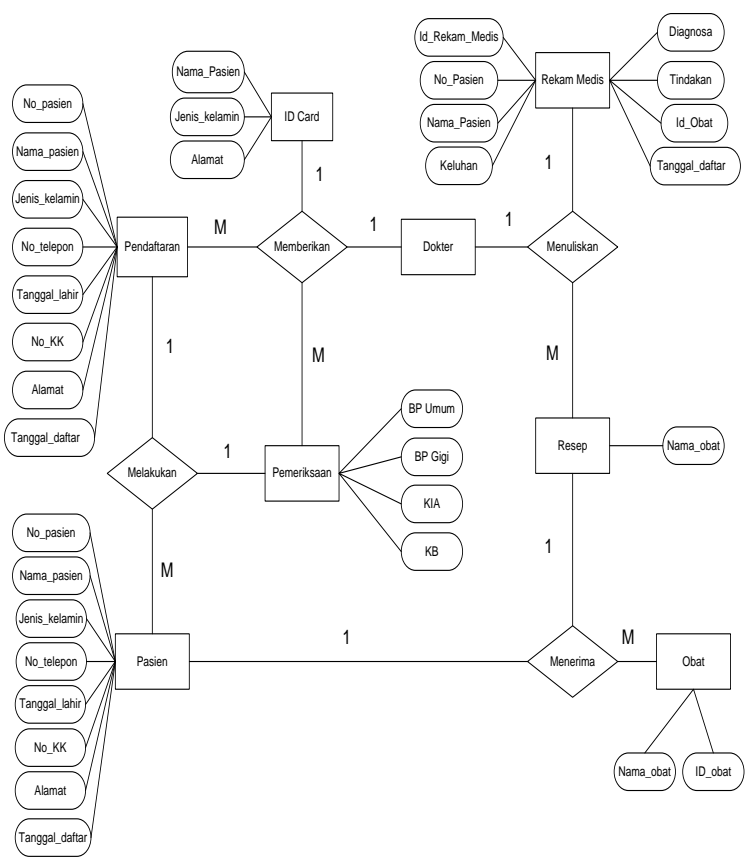

Gambar 3. ERD (Entity Relationship Diagram)

Berikut adalah tampilan layar dan hasil pengujian pada software program yang telah di buat dengan bahasa pemrograman Java. 


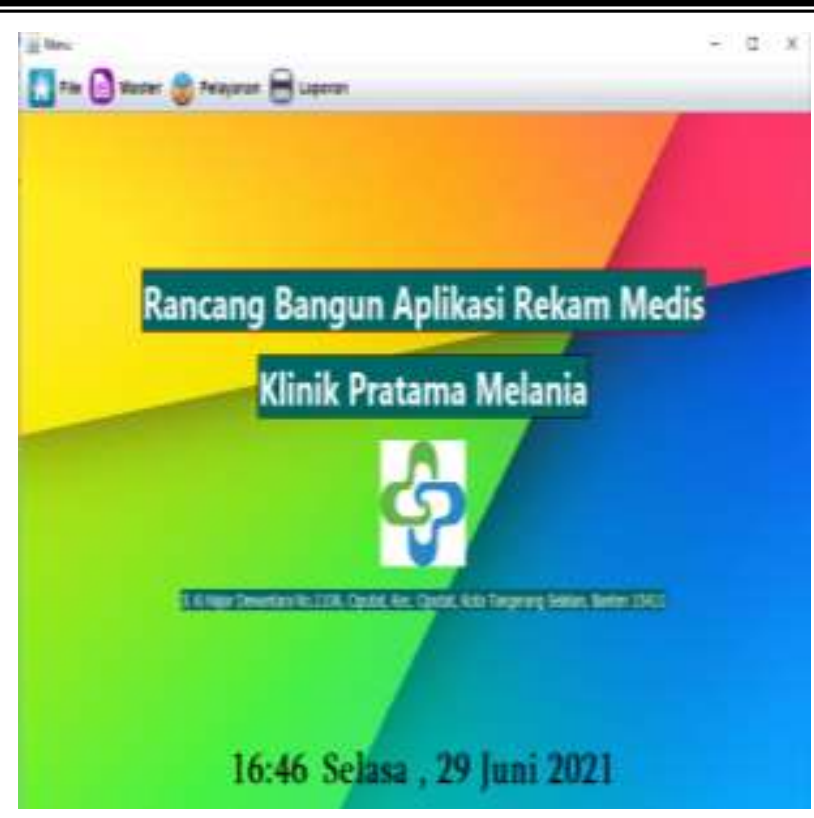

Gambar 4. Form Menu Utama

Layar di atas menampilkan tampilan Menu Utama pada Aplikasi Rekam Medis Klinik Pratama Melania. Pada layar utama tersedia menu bar yang terdiri dari master data yang digunakan untuk memasukkan data yang berkaitan dengan data pasien, data obat, data dokter, data pemeriksaan, data resep dan laporan-laporan. atis

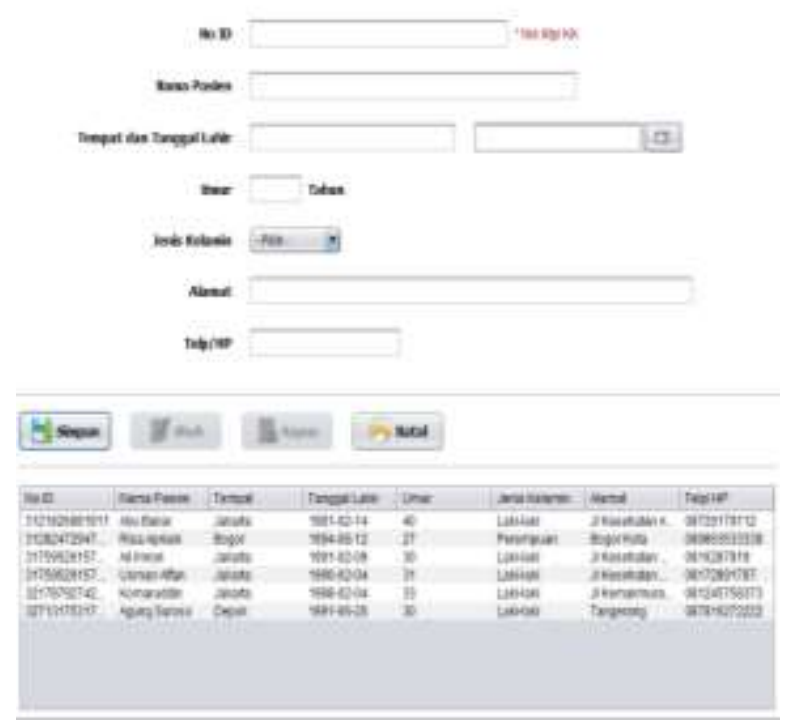

Gambar 5. Form Data Pasien

Layar di atas menampilkan tampilan form data pasien. Pada layar form data pasien untuk menginput data pasien yang terdiri dari No ID, Nama
Pasien, Tempat dan Tanggal Lahir, Umur, Jenis Kelamin, Alamat dan Telp/HP.

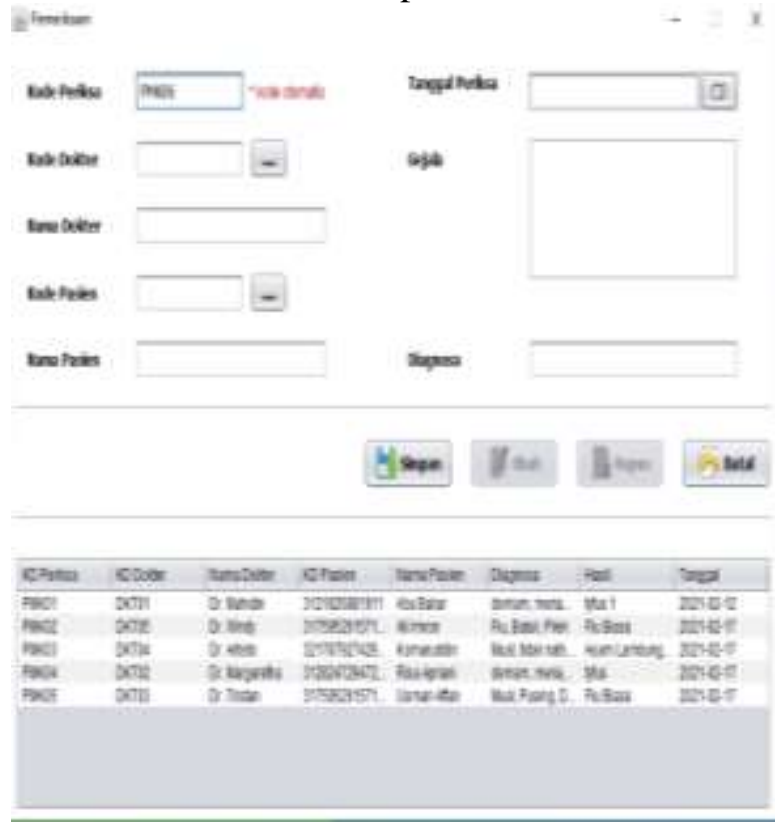

Gambar 6. Form Data Pemeriksaan

Layar di atas menampilkan tampilan form data pemeriksaan. Pada layar form data pemeriksaan untuk meng-input data pemeriksaan yang terdiri dari Kode Periksa, Kode Dokter, Nama Dokter, Kode Pasien, Nama Pasien, Tanggal Periksa, Gejala, dan Diagnosa.

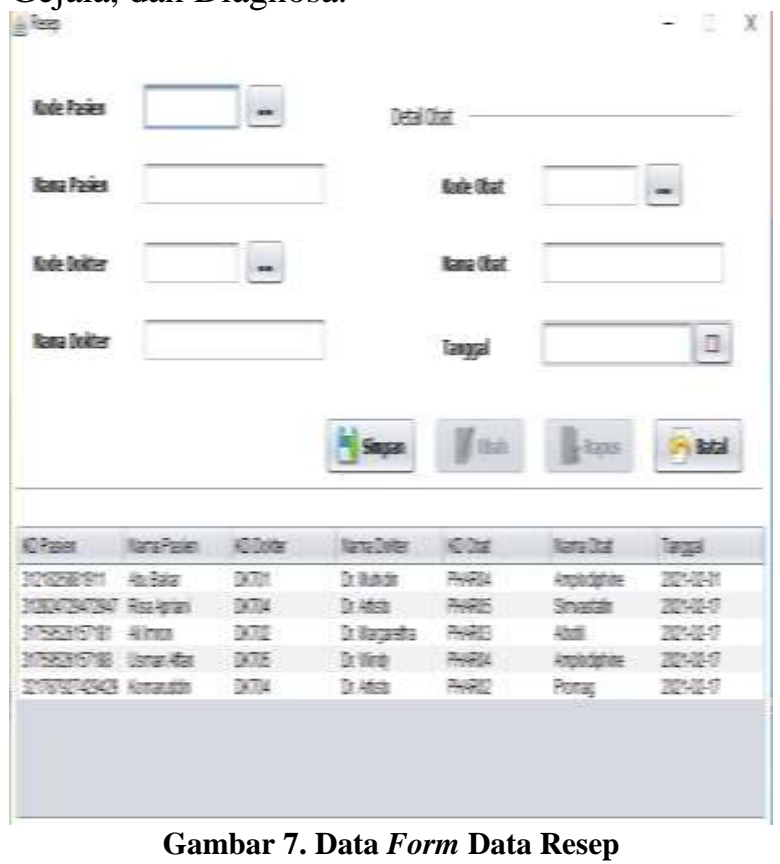

Layar di atas menampilkan tampilan form data resep. Pada layar form data resep untuk meng- 
input data resep yang terdiri dari Kode Pasien, Nama Pasien, Kode Dokter, Nama Dokter, Kode Obat, Nama Obat, dan Tanggal.

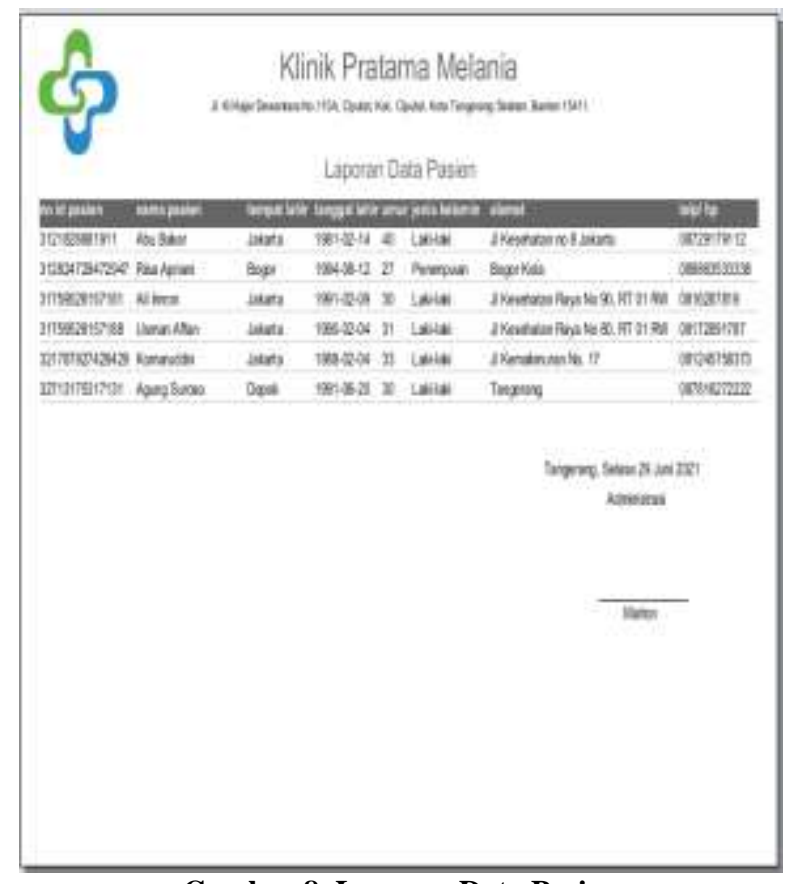

Gambar 8. Laporan Data Pasien

Layar di atas menampilkan tampilan form laporan data pasien. Pada layar form data pasien digunakan untuk mengecek laporan data pasien terdiri No ID, Nama Pasien, Tempat dan Tanggal Lahir, Umur, Jenis Kelamin, Alamat dan Telp/HP.

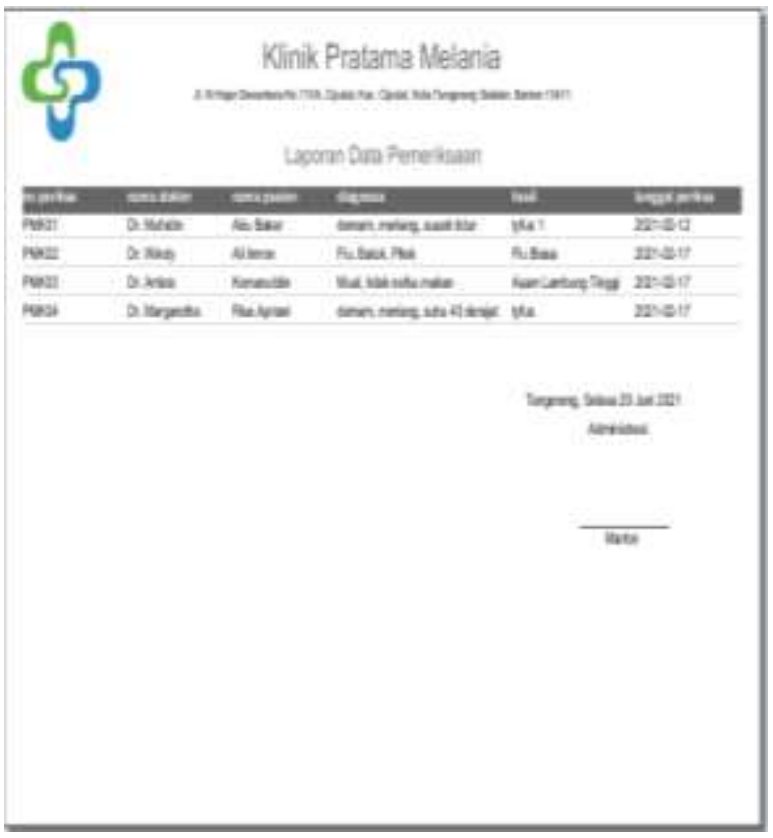

Gambar 9. Laporan Data Pemeriksaan
Layar di atas menampilkan tampilan form laporan data pemeriksaan. Pada layar form data pemeriksaan digunakan untuk mengecek laporan data pemeriksaaan terdiri No Periksa, Nama Dokter, Nama Pasien, Diagnosa, Hasil dan Tanggal Periksa.

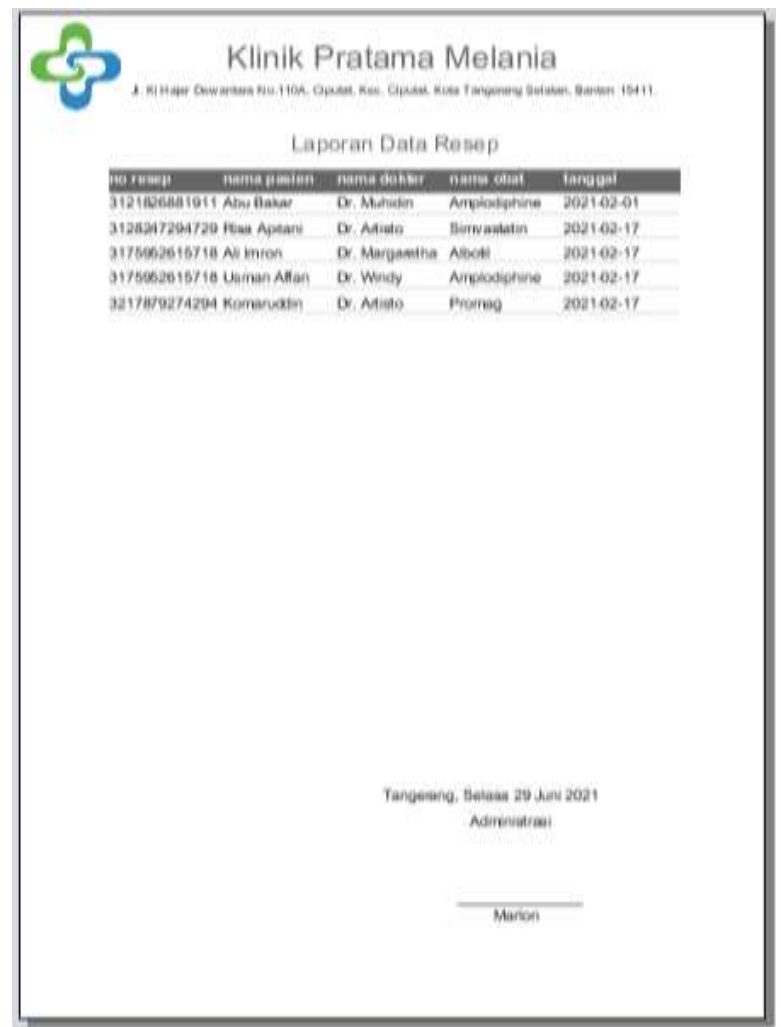

Gambar 10. Laporan Data Resep

Layar di atas menampilkan tampilan form laporan data resep. Pada layar form data resep digunakan untuk mengecek laporan data resep terdiri No Resep, Nama Pasien, Nama Dokter, Nama Obat dan Tanggal.

\section{SIMPULAN DAN SARAN}

Aplikasi yang baru pada Klinik Pratama Melania dapat menangani proses pencatatan dan pelaporan pasien sehingga dapat membantu admin klinik. Sistem aplikasi ini dapat memudahkan admin klinik dalam proses pembuatan laporan yang diberikan kepada pimpinan klinik setiap bulannya. Saran dengan penggunaan sistem informasi rekam medis pasien ini perlu dalam pengawasan dalam penggunaannya, sehingga aplikasi ini dapat berjalan dengan baik sesuai dengan kebutuhan pada Klinik Pratama Melania. 


\section{DAFTAR PUSTAKA}

Fatkhudin, A., \& Alifiani, D. N. (2017). Sistem Informasi Pendaftaran Pasien Pada Klinik dr. Veri Kajen Kabupaten Pekalongan Berbasis Android. Jurnal Ilmiah Edutic.

Handayani, T., \& Feoh, G. (2016). Perancangan Sistem Informasi Rekam Medis Berbasis Web (Studi Kasus Di Klinik Bersalin Sriati Kota Sungai Penuh - Jambi). Jurnal Teknologi Informasi Dan Komputer. https://doi.org/10.36002/jutik.v2i2.148

Prasojo, M. (2011). Pengantar Sistem Informasi Manajemen . bandung: CV. Remadja Karya.

Rahmat Tullah, A. A. (2019). Perancangan Sistem Informasi Data Pasien di Klinik Aulia Medika Pasarkemis. Sisfotek Global.

Satzinger, J. W., Jackson, R. B., Burd, S. D. (n.d.). System Analysis and Design in A Changing World. USA: Cengage Learning.

Sofica, V., Agista, S. T., Ningsih, R., \& Septiani, M. (2019). Aplikasi Pendaftaran Pasien Rawat Jalan Online pada Klinik Mulya Medika menggunakan Waterfall. Bianglala Informatika.

Sugiyono. (2016). Metode Penelitian Kuantitatif, Kualitatif dan $R \& D$. Bandung: PT Alfabet.

Sutabri, T. (2012). Analisis Sistem Informasi. Yogyakarta: Andi.

Syofian, S., \& Widyantoro, W. T. (2018). Sistem Informasi Pelayanan Pasien Rawat Jalan Menggunakan Aplikasi Pada Klinik Annisa Di Ciracas. Jurnal Teknologi Informasi.

Tyoso, J. S. P. (2016). Sistem Informasi Manajemen. Yogyakarta: DeePublish. 